Int. J. Electrochem. Sci., 12 (2017) $10348-10358$

Short Review

\title{
A Short Review of Synthesis of Graphdiyne and Its Potential Applications
}

\author{
Fan Chang ${ }^{1}$, Lijun Huang ${ }^{1}$, Yanrong Li ${ }^{2}$, Chaozhong Guo ${ }^{2}$, Qizhi Diao ${ }^{1, *}$ \\ ${ }^{1}$ Central Laboratory Yongchuan Hospital, Chongqing Medical University, Chongqing 402160, China. \\ ${ }^{2}$ Research Institute for New Materials Technology, Chongqing University of Arts and Sciences, \\ Chongqing 402160, China. \\ "E-mail: diaoqizhi@163.com
}

doi: $10.20964 / 2017.11 .70$

Received: 9 June 2017 / Accepted: 13 September 2017 / Published: 12 October 2017

Graphdiyne(GDY), a novel kind of two-dimensional carbon allotrope comprising sp- and sp2hybridized carbon atoms, was firstly proposed by Baughman group in 1987 and for the first time synthesized by Li group in 2010. The structure of GDY is related to that of graphene, but with the introduction of butadiyne linkages $(-\mathrm{C} \equiv \mathrm{C}-\mathrm{C} \equiv \mathrm{C}-$ ) to form $18-\mathrm{C}$ hexagons, which makes it possess large conjugated system, wide surface spacing, high chemical stability and semiconductor performance. The advanced and unique properties of GDY make it highly promising nanomaterial for applications in energy, catalyst, optoelectronic, separation membrance and sensor, and so on. Herein, we briefly review the recent progresses in the theoretical and experimental researches of GDY's synthesis, particular structure and properties, as well as the applications.

Keywords: GDY, catalyst property, semiconductor material, nanotechnology applications

\section{$\underline{\text { FULL TEXT }}$}

(C) 2017 The Authors. Published by ESG (www.electrochemsci.org). This article is an open access article distributed under the terms and conditions of the Creative Commons Attribution license (http://creativecommons.org/licenses/by/4.0/). 